\title{
Prevalence of Low Back Pain Among Women Living in Slum Areas of Dhaka City
}

\section{Sunam Kumar Barua"}

Nahida Sultana ${ }^{2}$

Department of Physical Medicine \& Rehabilitation Dhaka Medical College, Bangladesh.

Department of Physical Medicine \& Rehabilitation IHT, Dhaka, Bangladesh.

*Correspondence to:

\section{Dr. Sunam Kumar Barua}

Assistant Professor

Department of Physical Medicine \& Rehabilitation

Dhaka Medical College, Bangladesh.

Mobile : +8801819190812

E-mail : sunam1971@hotmail.com

\begin{abstract}
Objective: The aim of the study was to explore socio-demographic factors, risk factors for low back pain, relationship between developing low back pain with posture during work, any sort of treatment was taken or not etc. Methods: A cross sectional study was conducted to see the prevalence of low back pain among the women living in slum areas of Dhaka city.The study was done with a structured questionnaire to collect information from randomly selected 60 slum women from three selected slums in Dhaka city. Results: This study revealed that about $82 \%$ slum women had low back pain. Among them $76.7 \%$ were married and majority of them were house wives (46.2\%). The vulnerable age group for developing low back pain was 26 to 29 years. Most of the patients were illiterate (41\%), 36\% women had history of trauma, $58 \%$ women had history of lifting heavy weight. This study also showed that $46.9 \%$ of them pain was increased during work, persisted $>3$ hours in $59.2 \%$ women, $46.9 \%$ women had moderate pain. Pain was radiated mostly as tingling sensation in $39 \%$ women. Pain was relieved spontaneously among $41 \%$ women. Analgesics were taken by $73 \%$ women. Conclusion: Low back pain among slum women hampered the quality of their social and working lives.
\end{abstract}

Key words: Low back pain; Slum area; Dhaka City; Posture during work.

INTRODUCTION

Low back pain has become a costly burden to society and a leading cause of disability and loss of productivity. Low back pain is a symptom, not a specific disease. It is generally described as pain between costal margin and the gluteal folds ${ }^{1}$. Low back pain is usually described as discomfort in the lumbosacral region of the back that may or may not radiate to the legs, hips, and buttocks. The pain may be due to a variety of causes, and many individuals may never receive a clear diagnosis for the cause of the pain. Back pain affects $60-80 \%$ of people at some time in their lives. Although the prevalence has not increased, reported disability from back pain has increased significantly in the last 30 years. In western countries, back pain is the most common cause of sickness-related work absence, and in the UK $7 \%$ of adults consult their GP each year with back pain².

Among two thirds of the adults, low back pain is a major health problem ${ }^{3}$. A European study also shows that, 66\% patient suffered by moderate pain, 34\% suffered by severe pain ${ }^{4}$. Low back pain is one of the most common symptoms experienced by most of the people throughout the world ${ }^{5}$. It is estimated that 70 to $80 \%$ of the world's population has been suffered at least one group of events of back pain in their lifetime ${ }^{6}$. This condition may decrease the quality of life of individual and also become worse in daily activities. Usually low back pain is occurred between ages 25 and $50^{7}$. 
In a Chinese study claimed that the 1-year prevalence of LBP was $64 \%{ }^{8}$ Another research in UK shows that $75 \%$ people suffered with low back pain in every year ${ }^{9}$. Ratio found that low back pain is more common in female compared to male ${ }^{10}$. Almost every women will have at least one episode of low back pain at some time in her life. The pain can vary from severe and long term to short period. Usually it resolves within a few weeks. The most common risk factor for low back pain of women are heavy physical workload, lifting, awkward posture, static work posture, pregnancy, pushing \& pulling, body vibration, increased body mass index and life style $\mathrm{e}^{11}$. Bangladesh is a land of grueling poverty in terms of economic sense. Annually, the city draws an estimated 300,000 to 400,000 mostly poor migrants who provide critical employment for the city's industries and services. In 2010, the population of the city of Dhaka has projected at 17.6 million people, with up to $60 \%$ in the slums. The poor mainly live in slums scattered throughout the city. The society of Bangladesh is characterized by gender discrimination. Women are always victims of genderbiased policies, and treatments are also made in all spheres of live accordingly. Because of particular gender, women are the most suppressed, oppressed and exploited section of the society. Urban slum women are neglected and deprived in all spheres of their lives like family, society and state. They are deprived of adequate nutritious food, clothing, shelter, security of social services. Physical deprivation is a feature main in these women's live and it is at the core of poverty in the case of urban slum women ${ }^{12}$. Slum women are vulnerable to develop low back pain indeed.

\section{MATERIALS AND METHODS}

This study was conducted by using cross sectional study design. Random sampling was done among women aged 25 to 50 years living in the three selected slum areas (Nandipara, Trimohoni, Dakhkhingao) in Dhaka city in 2013. Researcher alone collected data by face to face interview in the slums and filled up the pre formed questionnaire by himself. Analysis was done by using SPSS 17 software. Descriptive statistics was used for data analysis. The results were presented with the use of simple percentage (\%). The collected data were illustrated with tables, bar charts and pie charts. Chi square test was done to find the associations between variables.

\section{RESULTS}

In this study, the participant's ages were $25-50$ years. Among them 27 to 28 year women had low back pain more followed by 31 to 32 years and 35 to 36 years.

Among the respondents $41 \%$ were illiterate, 22\% completed primary level, 17\% passed SSC and 20\% had higher education.

Among the respondents $88 \%$ were Muslims and only $12 \%$ were Hindu's.

Among the respondents, 76.7\% married, 8.3\% unmarried, 10\% widow, $1.7 \%$ divorcee and $3.3 \%$ separated.

Most of the respondents had four family members (35\%) followed by five members (24\%).
Among the respondents, 39 were house wife $(65 \%), 8$ were garment worker (13.3\%), 4 were house maid $(6.7 \%), 3$ were sells girl (5\%). Most of them had family income 5000-8000 Tk (35\%) per month followed by $8000-12000 \mathrm{Tk}$ (38.3\%), 12000$15000 \mathrm{Tk}$ (18.3\%), 15000-20000 Tk (8.3\%).

In this study, it was revealed that $57 \%$ of the respondents worked for 1-3 hours daily and only $22 \%$ of them worked $>8$ hours. Within total working period the slum women worked in sitting position for $1-3$ hours in $55.7 \%$, 3-5 hours in $15 \%, 5-8$ hours in 5\% and $>8$ hours in $22 \%$ daily.

Study showed that $58 \%$ slum women had history of lifting heavy weight.

Study showed that $48 \%$ slum women had habit of taking tobacco or alcohol.

Most of the respondents (63.3\%) had no history of trauma.

Presence of low back pain

Study revealed most slum women (82\%) had low back pain.

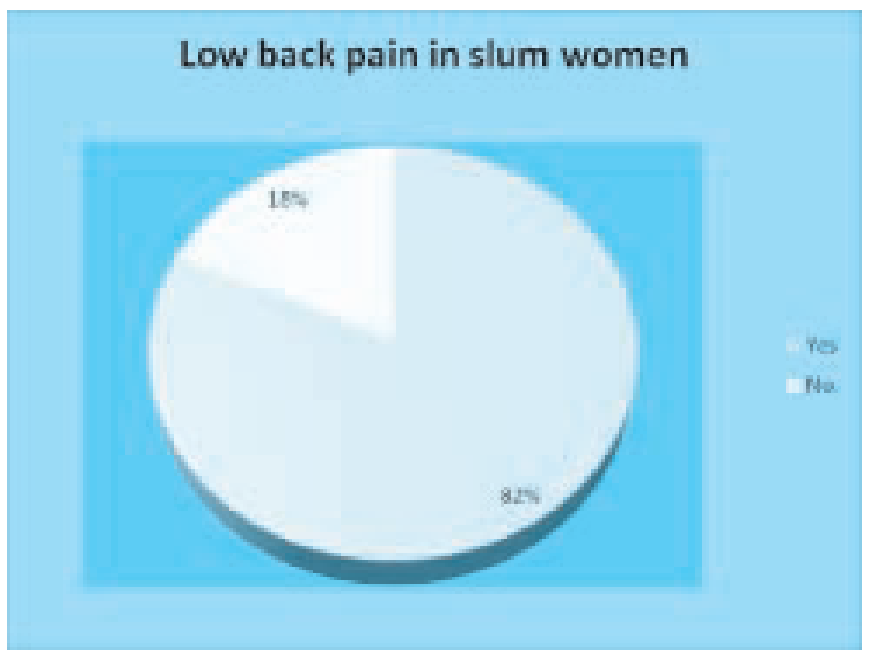

Figure 1 : Presence of low back pain

\section{Duration of pain}

Most of the respondents $22.4 \%$ had 5-10 years history of low back pain followed by $20.4 \%$ had $10-15$ years history.

Table 1 : Duration of pain

$\begin{array}{lcc}\text { Months/ Years } & \begin{array}{c}\text { Duration of pain } \\ \text { Number of women }\end{array} & \text { Percent } \\ \text { >6 months } & 4 & 8.2 \\ \text { 1 year } & 6 & 10.2 \\ \text { 2 years } & 6 & 12.2 \\ \text { 3-5 years } & 9 & 20.4 \\ \text { 5-10 years } & 11 & 22.4 \\ \text { 10-15 } & 10 & 20.4 \\ \text { 15-20 } & 3 & 6.1 \\ \text { Total } & 49 & 100\end{array}$




\section{The time when pain start}

This study showed that pain was aggravated during work among the most respondents (46.9\%), and $14.3 \%$ respondents had continuous pain.

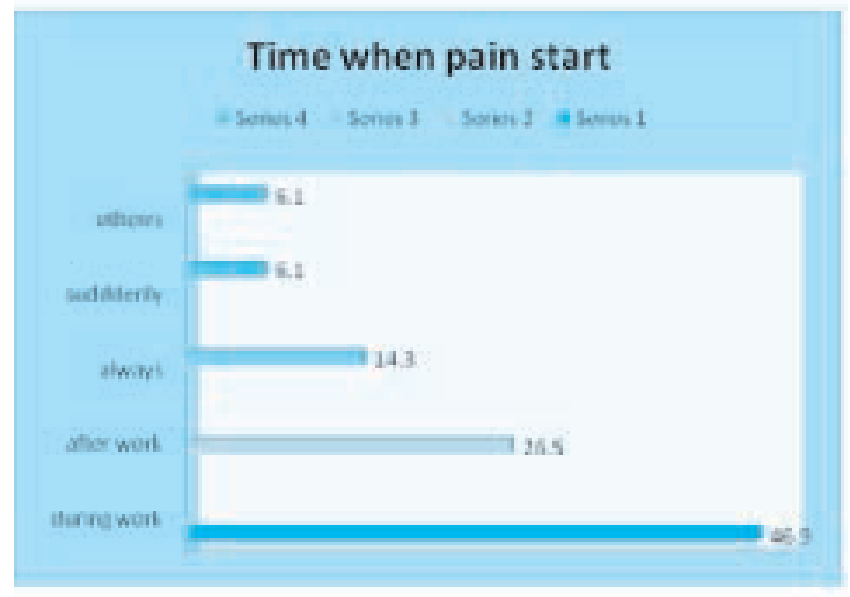

Figure 2 : Time when pain starts

\section{Pain persisting time (in hour)}

Maximum respondents (59.2\%) had pain persisting $>3$ hours.

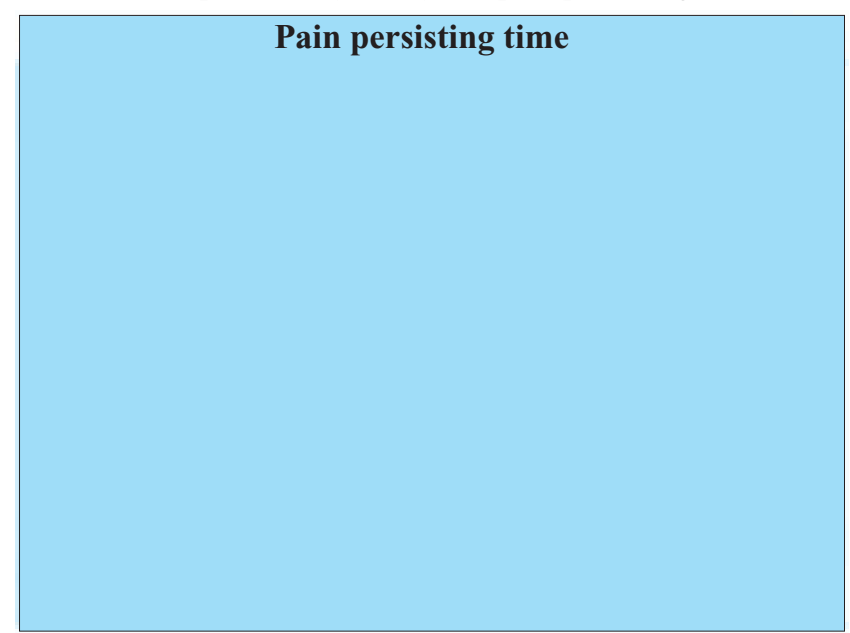

Figure 3 : Pain Persisting time

\section{Intensity of pain}

Most of the respondents (46.9\%) had moderate pain.

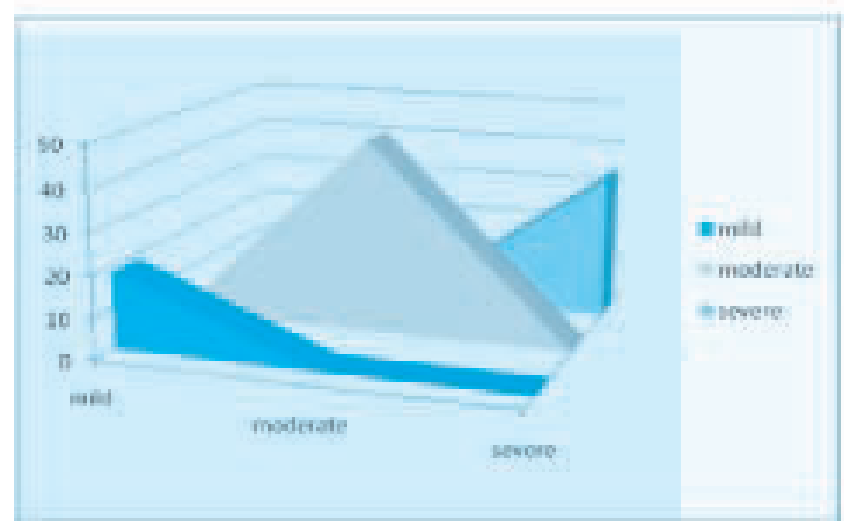

Figure 4 : Intensity of pain

\section{Radiation of pain in leg/ buttock}

$39 \%$ of the respondents had tingling type of radiating pain followed by numbness in legs (37\%).

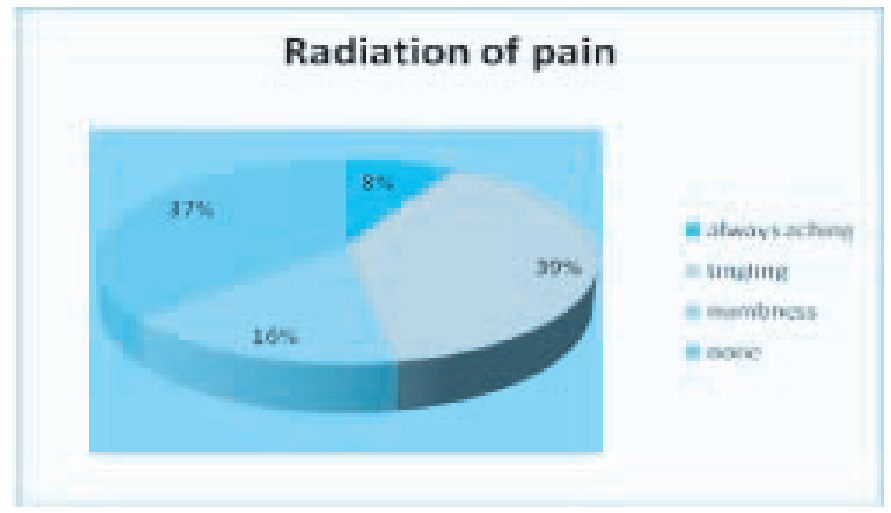

Figure 5 : Radiation of pain

\section{Precipitates work position for pain}

Study showed that sitting posture during work precipitated pain in $70 \%$ cases followed by standing work (16\%).

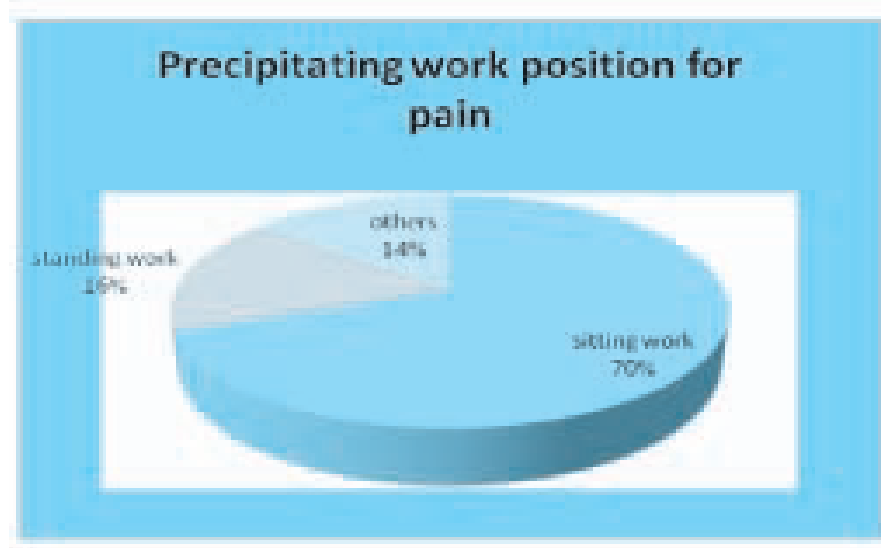

Figure 6 : Precipitating work position of pain

\section{Position reduces pain}

$75.5 \%$ of them, pain relieved by lying and $14.3 \%$ had no specific decubitus.

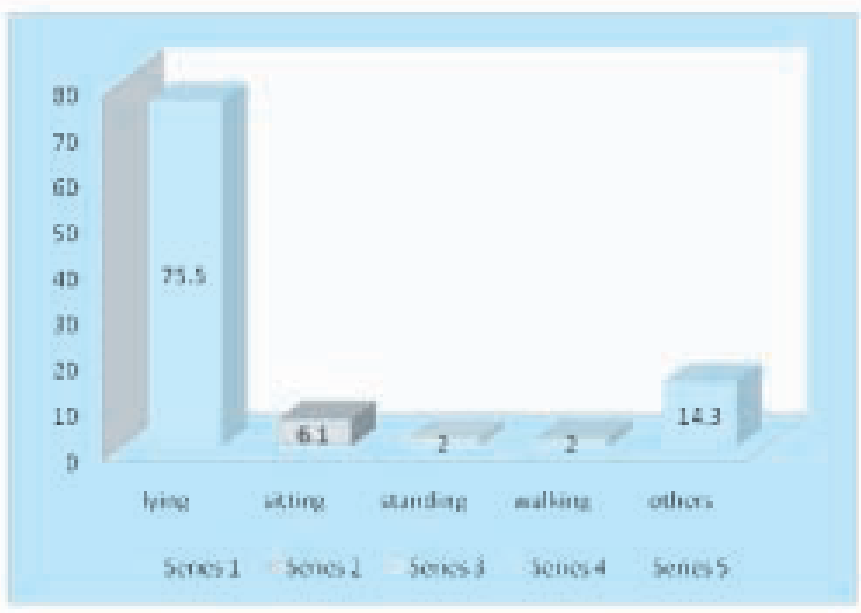

Figure 7 : Position reducing pain 


\section{Abstinence of work due to low back pain}

$43 \%$ of women having low back pain required to stop activities, while $57 \%$ can continue their activities with pain.

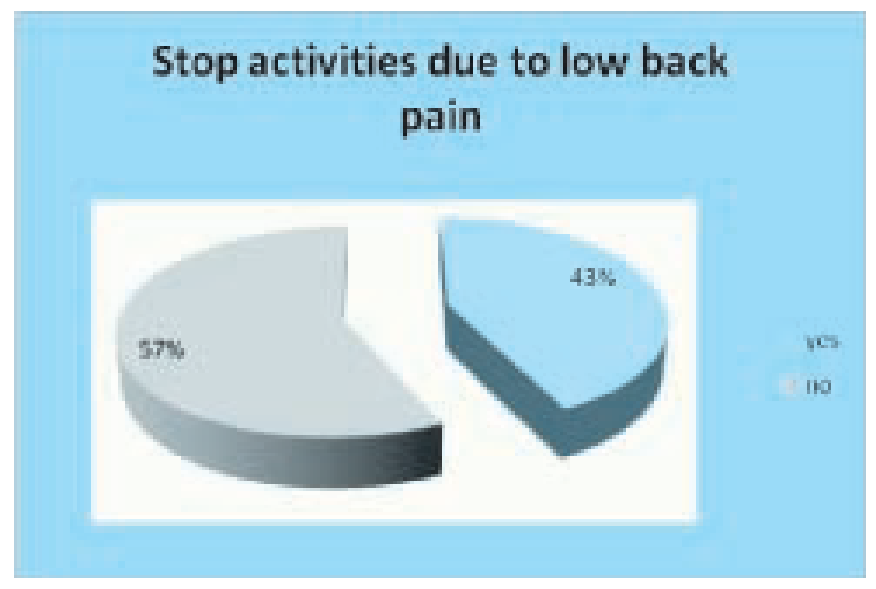

Figure 8 : Abstinance of work due to low back pain

\section{BMI}

This study results showed that, in the slum $8.1 \%$ women were under weight, $59 \%$ women were normal weight, $18.3 \%$ women were overweight, and $14.2 \%$ women were in obesity according to BMI score.

Table 2 : BMI of the participants

\begin{tabular}{lccccc} 
BMI score & $\begin{array}{c}\text { Under weight } \\
\text { BMI }<\text { 18.5 }\end{array}$ & $\begin{array}{c}\text { Normal weight } \\
\text { BMI 18.5 - 24.9 }\end{array}$ & $\begin{array}{c}\text { Over weight } \\
\text { BMI 25-29.9 }\end{array}$ & $\begin{array}{c}\text { Obesity } \\
\text { BMI }>30\end{array}$ & Total \\
$\begin{array}{l}\text { Number of } \\
\text { women }\end{array}$ & 4 & 29 & 9 & 7 & 49 \\
Percent & $8 \%$ & $59 \%$ & $18 \%$ & $14 \%$ & $100 \%$ \\
\hline
\end{tabular}

\section{DISCUSSION}

This study results showed that out of 60 participants 49 (82\%) have low back pain and 11(18\%) have no low back pain. MC Anil in his study in Southern India found $52.9 \%$ women had low back pain out of 403 women $^{13}$. Bener A in his study found LBP was more prevalent among women $53.9 \%{ }^{14}$. In Sikiru found LBP was more prevalent among female nurses $(57.6 \%)$ in Africa $^{15}$.

In this study the most vulnerable age group was found 26-29 years for developing low back pain. An epidemiology community health study stated that the most affecting age group was 30 to 39 aged people where men were $39.9 \%$ and women were $38.9 \%{ }^{10}$. Another study showed that low back pain usually occurs between 20-40 years of age ${ }^{16}$. On the contrary they found LBP was common in the age group between 40-59 years and it was $172(48.17 \%)$ followed by $60-79,20-39$ and 80 years group with $21.29 \%, 17.65 \%$ and $12.89 \%$ respectively in his srudy ${ }^{17}$. Low back pain was more prevalent in the $31-40$ years age group in a Nigerian study ${ }^{18}$.

This study revealed that $65 \%$ of the respondents were housewives, $13.3 \%$ garments worker, $6.7 \%$ housemaid. Most of the women were married $(76.7 \%)$.
Researcher also found that most of the slum women with LBP were less educated, $41 \%$ illiterate, $22 \%$ completed primary level, $17 \%$ SSC level, $10 \%$ HSC level. A Thai study stated that $46.1 \%$ were educated upto primary level who had back pain ${ }^{11}$.

The researcher found that $55.7 \%$ slum women work for $1-3$ hours per day in sitting position, $15 \%$ work for $3-5$ hour, $5 \%$ work for 5-8 hours and $22 \%$ work for $>8$ huors. Among them $58 \%$ women had history of lifting heavy weight. Most of them $(63.3 \%)$ had no history of trauma. Maximum of them $(46.9 \%)$ experienced, pain was aggravated by working which is similar to other study findings ${ }^{6,7}$.

The study showed that pain was moderate among $46.9 \%$ and severe among $34.7 \%$ women. Another study showed $66 \%$ of their respondents experienced moderate pain, $34 \%$ of them had severe pain ${ }^{4}$.

This study revealed pain was relieved spontaneously among $41 \%$ women. Another study showed $90 \%$ of low back pain resolved spontaneously within one month ${ }^{19}$.

In this study, about $73 \%$ were responded to medication (NSAIDs) and $27 \%$ were not responded to medication. A European study also showed almost half took nonprescription analgesics, NSAIDs (55\%), paracetamol (43\%), weak opioids (13\%). Two-thirds took prescription medicines, NSAIDs (44\%), weak opioids (23\%), paracetamol $(18 \%)^{4}$.

In this study, $8.1 \%$ were underweight, $59 \%$ normal weight, $18.3 \%$ over weight, $14.2 \%$ obesity according to their BMI score. Overweight and obesity was found association with development low back pain $(\mathrm{p}<0.05)$ that is similar to some other studies ${ }^{17,20,21}$.

In this study there was no association with tobacoo intake with development of low back pain $(\mathrm{p}>0.05)$ which is similar with Leboeuf - Yde C's review study but differs in another study $^{22,23}$.

\section{CONCLUSION}

Posture during work and regular household work is responsible for developing low back pain among women living in slum area. Bending activities aggravate this kind of pain. In slum their social and financial condition is related to the low back pain. The women with low back pain have no option and they have to have continued their work for survival, they do not take proper rest and often delay treatment due to their financial problem.

To prevent low back pain in the slum areas of Dhaka city, awareness should be developed regarding posture, early diagnosis $\&$ treatment, adequate diet and ergonomics.

\section{LIMITATION OF THE STUDY}

Study samples were very few thus didn't reveal the scenario of the women living in Dhaka city indeed.

\section{DISCLOSURE}

All the authors declared no competing interest. 


\section{REFERENCES}

1. Karen P, Barr and Mark A, Harrast. Low Back Pain. In: Braddom RL (editor). Physical Medicine \& Rehabilitation. Elsevier: Saunders. 2007;3:883.

2. Doherty M, Ralston SH. Musculoskeletal disease. In: Colledge NR, Walker BR, Ralston SH (editors). Davidson's principles \& practice of Medicine. Elsevier: Churchill Livingstone. 2010:1072. 2010;21:1072.

3. Witwatersrand, Johannesburg. Janwantanakul P, Pensri P and Moolkay P. Development of a risk score for low back pain in office workers a cross-sectional study. BMC musculoskeletal disorders. 2011; 12: 23.

4. Breivik H, Collett B, Ventafridda V, Cohen R and Gallacher D.A Survey of chronic pain in Europe : prevalence, impact on daily life, and treatment, European Journal of Pain. 2006; 10:287-333.

5. Kerssens JJ, Sluijs EM, Verhaak, Peter FM, Hanneke JJ and Hermans K. Back care instructions in physical therapy: a trend analysis of individualized back care program. Physical Therapy.1999; 79:286-295.

6. Nourbakhsh MR and Arab AM. Relationship between mechanical factors and incidence of low back pain, Journal of Orthopedic Sports Physical Therapy. 2002; 32(9):447-459.

7. Jackson AW, Morrow JR, Brill PA, Kohl HW, Gordon NF and Blair SN. Relations of sit-up and sit-and reach tests to low back pain in adults. Journal of Orthopedic Sports Physical Therapy. 1998; 27:22-25.

8. Barrero, Lope H, Hsu, Yi-Hsiang, Terwedow, Henry, Perry and Melissa J. Prevalence and physical determinants of low back pain in a rural chinese population. Spine. 2006; 31(23):2728-2734.

9. Webb, Roger MA, Brammah, Therese M, Lunt, Mark, Urwin and Michelle. Pevalence and predictors of intense, chronic, and disabling neck and back pain in the UK general population. Spine. 2003; 28(11):1195-1202.

10. Ozguler A, Leclerc A, France and Landre M. Insicidual and occupational determinants of low back pain according to various definitions of low back pain. Journal Epidemiology Community Health. 2000; 54:215-220.

11. Tomita S, Arphorn S and Muto T. Prevalence and risk factors of low-back pain among thai and myanmar migrant seafood processing factory workers in samut sakorn province, Thailand.Industrial Health. 2010; 48:283-291.

12. Hossain TM. Rapid Urbanizations and the Women in the Slums in Dhaka City. BUHN article. (Retrieved from: http://www.uhnbd.net/index.php/resources/buhn-articles/16-rapid-urbanizations-and-the-women-in-the-slums-in-dhaka-city on 26/07/2014 at 9:50 am)

13. MC Anil, SS Rowther, AS Thazhathekudiyil, et al. The prevalence and correlates of low back pain in adults: A cross sectional study from Southern India. International Journal of MEDICINE AND PUBLIC HEALTH.2013; 3(4): 342-346.

14. Bener A, Dafeeah EE, Alnaqbi K. Prevalence and correlates of low back pain in primary care: what are the contributing factors in a rapidly developing country. Asian Spine J. $2014 ; 8(3)$ : 227-236.

15. Sikiru L, Shamila H. Prevalence and risk factors of low back pain among nurses in Africa: Nigerian and Ethiopian specialized hospitals survey study. East Afr J Public Health. 2009; 6(1): 22-25.

16. Brian A, Casazza MD. Diagnosis and treatment of acute low back pain, American Family Physician. 2012; 85(4):343-350.

17. Chowdhury D, Sarkar S, Rashid MH, et al. Influence of body mass index on low back pain. Mymensingh Med J.2014; 23(1): 125-129.

18. Birabi BN, Dienve PO, Ndukwu GU. Prevalence of low back pain among peasant farmers in a rural community in South South Nigeria. Rural Remote Health.2012; 12:1920.

19. Hestbaek L, Leboeuf-Yde C and Manniche C. Low back pain: what is the long-term course? a review of studies of general patient populations. European Spine Journal. 2003;12(2):149-165.

20. Heuch I, Hagen K, Hench I etal. The impact of body mass index on the prevalence of low back pain: the HUNT study. 2010;35(7):764-768.

21. Bener A, Alwash R, Gaber T etal. Obesity and low back pain. Coll Antropol. 2003; 27 (1): 95-104

22. Leboeuf- Yde C. Smoking and low back pain. A systematic literature review of 41 epidemiologic studies. 1999; 24 (14): 14631470 .

23. Shiri R,Karppinen J, Leino-Arias P etal. The association between smoking and low back pain: a meta- analysis. Am J Med. 2010; $123(1): 87$ 